\title{
Investigation of the Collaborative Relationship between Industry and Academic Education in Open and Distance Learning: A South African Context
}

\author{
Mr. Patrick Nkhangweleni Mafenya \\ Institute for Open and Distance Learning \\ University of South Africa, Pretoria, South Africa \\ Email:mafennp@unisa.ac.za
}

\author{
Doi:10.5901/mjss.2013.v4n13p43
}

\begin{abstract}
Despite growing importance of collaboration in research there has been very few investigations of the relationship that exists between industry, commerce and academic education in an open and distance learning (ODL) environment. The purpose of this qualitative study is to explore and describe the collaborative relationship that exists between industry, commerce and academic education in ODL. Triggering the call for the integration of industry, commerce and academic education are increasing employers' criticisms that schools are delivering workers who lack problem-solving abilities and employability skillsall crucial for global economy. A shortage of skilled workers, combined with renewed interest in how to make education relevant to students has put the spotlight on technical vocational education and training. Furthermore, academic and vocational educators have been criticised for (1) providing curriculum that lacks participatory forms of learning, (2) promoting specific training and (3) encouraging a dual structure that segregates academic and vocational education. The research question: What collaborative relationship exists between industry and academic vocational education and training? provided the focus for the study. In-depth interviews were conducted to collect data. The collected data were digitally recorded, transcribed and analysed using Collaizi's data analysis framework. The findings revealed that integrating academic and vocational education not only provides students with the necessary transferrable skills that employers want, but it also provides a mechanism for engaging those who have not thus far been engaged by academic learning.
\end{abstract}

Keywords: Collaboration, academic education, technical vocational education and training, open and distance learning.

\section{Introduction}

The collaboration between industry, commerce and the academic world has always been an important but complex topic (Henderson \& Smith, 2002). Academic-industry interaction has received considerable attention in recent years. Technical and vocational education and training is defined as any education or training programme, course, module or scheme that contributes towards the collective development of the necessary knowledge, skills and attitudes required for further education and training and/or for gaining employment in a particular trade or occupational area (Smith, 2000). Due to the rapid evolution of the business environment and the vast transformation throughout the academic realm, the subject is now hotter than it has been. Although most academics support the concept of integrating academic and vocational education and recognise the benefits it affords, implementation of integrated curriculum and instructions is seen as problematic. This is where this paper aims to make a contribution. Technical vocational education and training is a direct means of providing workers with skills more relevant to the evolving needs of employers and the economy. To merge the two in an integrated approach to educational system requires new forms of organisational delivery (Grubb \& Kraskoukas, 1993). Industry-academic collaborations are like partners skilled in different dances trying to reach a compromise between waltz and salsa. Rhythms, pace, and expected outcomes can be frustratingly at odds, as university researchers prioritise education and basic research and corporate scientists pursue products and profits.

Success depends on finding common goals and negotiating plans that pay off financially and intellectually for all parties. The various parties work closely together to share knowledge and learn from each other in order to improve the end product. When industry and the academia collaborate, each party has certain expectations of the other side-the industry expects innovative and state of the art-lecturers to secure high quality education, valuable knowledge and ground breaking methodologies, while the universities expect their students to be given business experience through internship and opportunities to put their skills into practice. The academics also expect to be given the opportunity to transfer theoretical ideas into practical projects and to implement research in the real world.

Companies which do not have a close relationship to the academic community are expected to advance slower 
(Vahasantanen \& Etelapelto, 2009). By being out of touch with university, its students and young professionals, they become less attractive as prospective employers and often find it more challenging to recruit graduates and commit them for their 2-3 professional years. It therefore seems much more effective for industry to collaborate with the academic world than not. According to Smith (2002) collaboration between industry, commerce and the academia are promoted by open innovation programs, which have become a near-universal model for research and development. Skills acquisition is vital for an economy to compete and grow, particularly in an area of economic integration and technological change. Since team teaching is a requirement of most integrated courses, teachers must receive training in ways to integrate learning concepts (Lankard, 1993). In the following sections the researcher reviewed the literature on industry-academic collaboration. After an introduction to the research design and interviews the researcher presented the results using the interviews as unit of analysis. The researcher concluded by considering the implications of industry, commerce-academic collaboration in an open and distance learning context.

\section{Literature Review}

This literature review will attempt to provide a concise but informative overview of the literature regarding collaborative relationship between industry, commerce and academic education in open and distance learning. There is huge literature on collaborative relationship between industry, commerce and academic education. Industry-academic collaboration has always been a topic of discussion in both sides (Jackson, 2010). Indeed, the collaboration, world over, is quiet limited. The integration of academic and vocational education is a curricular and instructional strategy that makes learning more available and meaningful to all students. Integration also fosters teacher collaboration in curriculum planning and coordination of instruction.

The need to prepare young people to feel the jobs needed by the changing economy is a problem of increasing concern (Reagan \& McEvily, 2003). They are not provided with either the academic skills needed to attend a college or the vocational skills. Collaborative or joint research refers to arrangements under which universities and industry cooperate to pursue research objectives together. Contract research consists of research carried out by universities under the direction of industry clients (Santoro \& Betts, 2000). These different types of university-industry relationships can be expected to have varying impacts on academics' generation of academically relevant knowledge. Such initiatives seek to encourage academic interaction with industry in the expectation of the benefits that will accrue to both academia and industry. Integration is an ideal way to help universities retain students not interested in the benefits of an academic education per se, but aware of the advantages of entering the job market with skills.

Program components that allow students to work provide them with a needed income, hands-on experience in their chosen field, and contact with employers who may offer them career path jobs after graduation (Avis, 2007). While the benefits noted above suggest that universities should move toward integrating academic and vocational education, there are important constraints that may have to be overcome. Though there are many valid reasons why there are poor linkages between industry, commerce and academia, the main reason is the lack of suitable forums and platforms to facilitate this collaboration (Smith \& Betts, 2000).

In the South African context, there is a high shortage of skilled manpower and this shortage could only be dealt with through high level collaboration between industry, commerce and the academia. One of the core functions of academic institutions is to provide educative teaching and most of what the academics teach is of interest to industry (Bohloko \& Mahlomaholo, 2008). Therefore, a natural collaboration possibility is for the academic faculty and institutes to conduct training in topics of interest for industry. Today in the world that is driven by intellectual property, there is an increased interest in collaboration in the area of research. Though academicians in most institutions engage in research, collaboration in this area is possible only if the industry has a need for research.

The rift between academic and vocational education has been especially magnified by the physical isolation of vocational facilities and such isolation promotes psychological segregation of the two, further damaging the image of vocational education (Engestrom, 2001). Furthermore, to help mend the rift, vocational and academic teachers need opportunities to reflect on and discuss the objectives of their programmes in relation to one another. How beneficial it would be if vocational and academic teachers could work together to help all students. Achieving collaborative relationship based on cooperation would require not only attention to attitudes toward vocational and academic education by both groups but efforts toward collegiality of education in general. Industry-university collaboration must be aligned with the company's research and development strategy and address a tangible need of the company (Baker \& Henson, 2010).

It is important to make sure that there is a tight link between industry and the academia. The point is that there 
should be a vision within industry about what the academia projects will provide to the industry. Academic projects with link to industry interests create a strong continuing basis for collaboration when the research complements the industry's own research and development or when the project is considered important for the industry's technological leadership.

Furthermore, when industry personnel work on projects that are linked to the academia, the knowledge flows connected with the collaboration are heightened, providing additional pathways for up-take of the results (Dacre Pool \& Sewell, 2007). It is imperative that the academic researchers visit the industry and interact with the personnel because such visits can facilitate the creation of strong personal relationships. Industries are increasing interaction with universities by sending personnel on extended stay as visiting researchers, by providing opportunities for faculty sabbaticals and leaves at the company and by providing student internships. For years, academia and industry have collaborated on innovative research often with mixed results (Guile \& Griffths, 2001). On the surface, the marriage between university research and industry seems like a natural and productive union. Unfortunately, many industries have failed to make effective use of academic or university research. Transferring academic research to the industry in a useful and meaningful way has been challenging.

\section{Theoretical Framework}

Every serious researcher is aware of the importance of theory in teaching, learning and research. Theory teaches us what we know and also what we do not know and guides us in our research. "Research that is not grounded in theory is wasteful" (Moore, 1991, p.1-6). Against this back drop this study has made use of Nonaka's (1994) organizational knowledge creation theory to analyse industry-university relationships. This theory was regarded as the most suitable one for this study because of its ability to respond to the research question and the research objectives. According to Nonaka's knowledge creation theory, individual's knowledge is secured through networking mechanisms like strategic training and job rotation. The theory suggests that innovation outcome increases when a company or industry supports students' personal growth through the courses given at the universities. A student accumulates direct experience by working with different company issues.

\section{Research Methodology}

A qualitative phenomenological approach was used to highlight how the relationship between the industry and the academia can be fostered in order to bring about industry-academic collaboration. Phenomenological research seeks to understand the meaning and essence of the lived experiences of a phenomenon or group of people (Patton 2002). The researcher designed the study to capture the large variety of ways in which academics engage with industry. The researcher selected respondents from a single research-intensive South African university to minimise organisational variation.

To capture the views of the participants on the subject industry-academic collaboration the study utilised unstructured interviews with personnel from the University of South Africa (Unisa) and two industries that are located not far from the institution. In this study six faculty members who were assumed to have a high possibility of being involved in university-industry collaboration were intentionally selected because it was the intention of the researcher to include participants who would help him to answer the research question: 'What collaborative relationship exists between industry, commerce and academic education in open and distance learning institutions?' The participants were drawn from the Colleges of Science, Engineering and Technology (CSET), Agriculture and Environmental Sciences (CAES), Economic and Management Sciences (CEMS). Purposeful sampling was used because the idea was to get people who have first-hand experience on industry-academic collaborations. These colleges were chosen because they are largely responsible for providing training to people who after qualifying in their studies are normally employed in the industrial sector. Two basic inclusion criteria were considered for this intentional sampling:

- The academic department of the sample must be one where there are disciplines with which industry may want to collaborate

- The academicians to be interviewed were assumed to have higher potential for university-industry collaboration

In this research study the researcher visited about two industries were in-depth interviews were held with the senior management and workers of both large and small firms. The participants' profile included gender, academic department and level of involvement in academic-industry collaboration.

Most of the study participants were from the Colleges of Engineering, science and technology, Agriculture and 
Environmental Sciences. Given that the aim of this study was to explore and describe the collaborative relationship that exists between industries and the academia in open and distance education, interviews were considered the most appropriate and effective method for addressing the research question. Data were collected until saturation was reached as this was shown by the participants' failure to come-up with new themes. Data were analysed through the use of Collaizi's (1978) data analysis framework. This framework was chosen because of its ability to provide a clear step by step phenomenological data analysis processes. The following stages were employed to analyse data:

- Step one: The researcher read and re-read the transcribed-word-for-word interviews to make sense of them and acquire a feel for each description

- Step two: Significant statements which pertained directly to the proposed phenomenon from the description were extracted.

- Step three: Meanings were formulated after analysing each significant statement. The researcher again reread the original protocols to make sure that the original description was captured in the extracted significant statement meanings

- Step four: Formulated meanings were organised into clusters, which allowed themes to emerge.

- Step five: Themes were integrated into an exhaustive description. The researcher made a concise statement of the exhaustive descriptions and provided a fundamental statement of identification. In order to understand students' experiences the researcher had to move from individual phenomenological structure to the general description of situated structures. It is through this process that several themes were identified from each participant and then clustered into a number of general themes that appeared to be common to all the participants' descriptions. The final step in data analysis involved an interpretation or meaning of data, and it was at this stage that the clustered themes and meanings were used to develop the textural descriptions of the experiences. From the textural and structural description an integration of the meanings and essences of the phenomenon were constructed. This included making use of the verbatim examples from the transcribed interviews.

- Step six: The researcher presented a concise statement of the exhaustive description to the original participants of the study in order to verify the statement (data validation).

\section{Rigour Establishment}

In considering rigour in any qualitative research, including phenomenological approaches, there is need to determine whether the study is believable, accurate, and right, and whether it is useful to people beyond those who participate in it. This necessitates a consideration of the concepts of validity, reliability and generalisability. However, according to Lincoln and Guba (2000, p.15-25) the customary evaluation criteria of validity, reliability, generalisability, and objectivity in quantitative research are sometimes not applicable to phenomenological research. Lincoln and Guba (2000, p.143) suggested that for qualitative studies to achieve "trustworthiness", these four concepts: credibility, transferability, auditability and confirmability should work together. However, to achieve rigour, this study has used credibility, audit trail or confirmability and ethical considerations as suggested by Drisko (1997, p.191) and Licoln and Guba (2000, p.143).

\subsection{Credibility}

Credibility of this research was achieved in several ways. The notes that the researcher made in his notebook provided detailed reflection to ensure sufficient attention to bracketing. Bracketing made it possible for the researcher to focus on the respondents' experience, while allowing informants to construct and give meaning to their own reality. In phenomenology, bracketing is a means of ensuring the researcher presents faithful descriptions of the experience. Every effort was made to stay faithful to participants' words and descriptions throughout the analysis without changing the meaning or intent of descriptive passages.

To increase the credibility of the study, the researcher also used member-checking to verify that the interviews were a faithful depiction of their experiences. Lincoln and Guba (2000, p.143) describe member-checking as the most crucial technique for establishing credibility in a study. It consists of taking data and interpretations back to the participants in the study so that they can confirm the credibility of the information and narrative account. The most popular strategy to achieve this is to convene a focus-group of participants to review the findings. Throughout this process the researcher asked participants if the themes or categories make sense, whether they are developed with sufficient evidence, and whether the overall account is realistic and accurate. Furthermore, data validation was achieved 
by giving participants an opportunity to correct errors and challenge the statements that were perceived as wrong interpretations of their experiences.

\subsection{Audit-trail}

This refers to the adequacy of information reported, from the research question and protocol for data collection through the raw data, through various stages in the analysis of data to the interpretation of findings. One of the ways research can be shown to be sound is for the research process to be clear, so that another researcher can understand the methods and process of the researcher and research. To increase the study's reliability, the researcher started by providing an audit trail of how he went about collecting data from the participants. This was followed by his disclosure of personal orientation and context. The researcher did this to make sure that the outcome of the study was not influenced by his pre-conceptions of the phenomena under investigation.

Furthermore, the researcher increased data reliability by having intensive engagement with the material and iteration between data and interpretation. In addition, the researcher kept a research notebook throughout the data collection and analysis stages. Aside from the methodological steps provided in this study, the research notebook was written during the interview and analysis processes, and included several aspects: notes on data collection, ethical conduct, data analysis, and insights into the topic area.

Since the researcher has utilised, besides other instruments, the in-depth interviewing, which was explanatory in nature, and one that was on a voice-recorder, which is playable over and over again to ensure authenticity of findings, it was thus anticipated that high level of validity could be achieved. The researcher made sure that the interpretations given were technically correct and were grounded within the data through the use of verbatim illustrations.

\subsection{Ethical considerations}

This study was conducted in accordance with all the requirements of ethical considerations. Since this research study dealt with human-beings, care had been taken to make sure that the participants were protected from harm. The researcher explained the purpose and objectives of the study to the participants so that they could participate as informed volunteers. All the information shared between the researcher and the participants were treated as confidential. An undertaking was made to make sure that the information provided by the participants will be used for research purposes only. Participants were allowed to withdraw from the research study if they wanted to do so without any penalties. Those participants who agreed to take part in this study were given a consent form to append their signatures as a sign of agreeing to the terms and conditions of the interviews. Furthermore, the researcher also applied for an ethical clearance certificate from the University of South Africa's Ethical Committee, which was granted. Participants were also allowed to review and confirm or alter the research data to correspond to their perceptions of their experiences.

\section{Discussion of the Study Findings}

On the basis of the data collected, recorded and analysed the findings of this study fall into the following themes: lack of cooperation between industry and the academia, dilemma of collaboration, lack of government policies to enforce industry-academic collaboration, stake-holder attitudes, industry-academic collaborative barriers and lack of previous success experience in collaboration. The findings of this study were presented in terms of the participants' experiences that they shared with the researcher at the time the interviews were conducted.

\subsection{Theme one: Lack of cooperation between industry and academia}

The study found that currently there is little co-operation between industry and the academia due to the fragmentation of the education systems. The current government's policies are not talking to the policies implemented by industry and commerce. In many cases, projects are often led and carried out by academics and address topics less directly relevant to industry, and as such partners tend to be less involved and hence interactive learning effects are reduced. One of the participants had this to say: "What I find is that there is a growing involvement between universities and industries to work together but it is very limited. Our education system is not directly talking to our industrial needs.' The above quotation indicates that unless there is cooperation between the government and the industry, collaboration will be a far-fetched 
dream.

\subsection{Theme two: Dilemma in collaboration}

The data collected shows that academic research is more likely to have positive impact on industry if the academic researchers have a strong knowledge of the business setting, industry practices and how the research findings fits company strategy as suggested in the following statement: "Business is interested in collaborating with universities as long as they can help them generate more profit. Universities are interested in collaborating with industry provided they will be able to produce more publications at the end of the day". The study revealed that academics usually face potential dilemma when they collaborate with industry. Furthermore, the researcher found out that commercialisation is the primary rationale informing academics' involvement with industry.

The study also discovered that for a healthy collaborative relationship to exist between industry and the academia they should share research infrastructure where both academia and industry can easily meet. It was also revealed that through collaboration both can develop a culture that promotes innovative ventures.

\subsection{Theme three: Lack of strong government policies to enforce industry-academic collaboration}

This research study found that it was regarded as the responsibility of the government to enforce industry-academic collaborations, however, not much seems to be happening in this area, even though both sides stand to gain. Another participant expressed the following views based on industry-academic collaboration: "The high unemployment rate that we are facing today was exacerbated by the failure of our government's policies to be able to foster a good working relationship between industry and academic education. I think had the government planned properly, our students should have been work-ready when leaving the colleges or universities." The study further found out that where possible, industry mentors could be used for mentoring those students who have registered for masters and doctoral degrees. Successful integration of academic and vocational education is very closely related to, and aided by, strong instruction in all aspects of an industry. From the above analysis the study revealed that academics face a potential dilemma when they collaborate with industry. The findings indicate that, where there is understanding between industry and the academic education and training, collaborative working does indeed have the potential to promote learning and knowledge transfer in a number of ways. Furthermore, the academicians found that the policies and regulations prescribed by the government to encourage university-industry collaboration were not sufficient and consequently affected collaboration negatively. Because of the reason that the government's legal adjustments aimed at developing university-industry collaboration were not effective at the desired level, there is a lower possibility of academicians being involved in joint studies with industry.

\subsection{Theme four: Stakeholder attitude to collaboration}

The study found that the participants identified a number of major barriers to collaborative relationship, namely the attitudes among the various stakeholders. Both academic and vocational teachers play an important part in the education of the youth today. Unfortunately they often see their roles not only as different but competitive as well. This attitude is frequently manifested in a rift between academic and vocational education, which serves only to harm the students (Berry \& Bailey, 1992). Consequently, a persistent theme in the interviews was that for collaborative working to function properly both, industry and the academia should be willing to encourage and incentivise this way of working. For instance, many participants spoke of the benefits brought by long term collaborative relationships. One participant who is a factory manager had this to say: "If we want to see industry-academic collaboration working properly, it is imperative for the leaders to encourage their employees to see each other not as competitors but as people who should work together for the success of both parties." This highlights the potential of benefits of long-term, continuous collaborative working, as opposed to the single-project relationship that has been traditionally the case in education. The study discovered that the field of social sciences does not take a great in joint-study projects as the field of technical sciences. From the industrialists' point of view, when university-industry collaboration is spoken of, collaboration with technical disciplines generally comes to mind.

The study found that various forms of collaboration existed between the university and the industry, for instance, in training and consultancy, training and technical research. However, the study also discovered that there are several factors that are making it very impossible for university-industry collaboration to be effective and efficient in order to bring 
about economic growth in our communities.

\subsection{Theme five: Industry-academic collaborative barriers}

The results of the study had shown that industry-university collaboration is hindered by low level of interest by both stakeholders to work together. Data obtained from the research conducted revealed that academicians are aware of the need to be closely involved in field studies, and they think that not giving the necessary importance to field studies may negatively affect collaboration with industry. Therefore, the study contends that it would not be wrong to say that there is a requirement for the legal infrastructure to encourage university-industry relationships at an effective level. One participant indicated the following when talking about some of the most important well-known barriers that affect university-industry collaboration: "Even if we enforce industry-academia collaborations barriers like lack of adequate resources on industry and university side, cultural differences between industry and university counterparts, inflexible academic research timetables, long-term orientation of academic research, incompatible reward systems with focus on publishing versus protecting results, risk related to obtaining control over university inventions through intellectual property rights, industry-university collaborations struggling with exploitation of too premature technologies will always be there." The above statement is an indication that for industry-academic collaboration to succeed all hands should be on deck.

\subsection{Theme six: Lack of previous success experience in collaboration}

Another important factor affecting university-industry collaboration is previous experience. Lack of success or having bad experiences negatively affect any future collaboration. The findings reveal that previous bad experiences are viewed by academicians as a factor hindering university-industry interaction. Participants from both academia and industry, highlighted many of the issues that can make such communications difficult and provided innovative ideas on how academia and business could collaborate more effectively together. One of the senior managers from the industries was heard saying: "The challenges that we have as managers include a lack of trust over issues such intellectual property, uncertainty about the potential benefits of working together, and the difficulty on both sides of finding the time for initial exploratory conversations." Though industry-academic collaboration can be challenging, the benefits certainly outweigh the risks.

\section{Recommendations and Implications}

This study was only an attempt by the researcher to shift our educational thinking into a more industrial-academic collaboration because of the poor linkages that usually takes place between the two entities. The growth of research collaboration and its expanding literature convey mixed messages to those responsible for managing research. There are two broad implications. One concerns future research on industry-academic collaboration and the second concerns the way benefits may be harnessed in institutional form. Industry collaboration has differing effects on the production of academic knowledge, depending on the objectives pursued. In spite of the claims that the academic and the industrial worlds are converging, the study revealed that both sides are benefitting from close collaboration to suit their own purposes (Nelson, 2005). This study recommends that there is need for deliberate dissolution of separation of education into academic and vocational camps.

Participation in one should not prelude involvement in the other and placing importance on one should not relegate the other to an inferior status. Team teaching by academic and vocational teachers is also a possibility. Regardless of partners, collaborative success rests on three principles: a mutual interest in a common achievable goal, constant communication about expectations, timelines, and rewards, transparency throughout the project. It is important to have conversations in which all partners explain what they need from collaboration: funding, deliverables, publications, patents and so on. A good industry-academic partnership should be set up from the start as a win-win for all sides. While industry-academic collaboration is both highly valued and widely practised by universities and further education and training colleges, recently appointed staff in particular, expressed concern over a lack of leadership in fostering collaborative work. Relationship between academia and industry are increasingly intimate and commercial. While opportunities are created for each partner, there are also important conflict of interest issues. Particularly challenging is ensuring that universities maintain their traditional role in public science while partnering with a commercial entity with a tradition of proprietary science. Finally, the study contends that increasing access to technical vocational education and 
training serves the dual purpose of keeping more students in the education system while training them to fill the current gaps in the skilled worker sector.

\section{Conclusion}

This descriptive study explored and described the relationship that exists between industry and the academia. A qualitative phenomenological approach was utilised to elicit the experiences of the participants who are found in those two entities. The study revealed that there is lack of cooperation between industry and the academia. Furthermore, the study found that there is lack of will from the government to put in strong policies and procedures to enforce industryacademic collaboration. Other important factors that were found to be negatively affecting industry-academic collaborations were the stake-holder attitudes, industry-academic collaborative barriers and lack of previous success experience in collaboration. However, the evidence presented here demonstrated a need for the two to work together if all parties are to bring changes in our economies as a country and a region.

\section{References}

Avis, J. (2007). Engestrom's version of activity theory: A conservative praxis? Journal of Education and Work, 20 (3), 161-177.

Baker, G. \& Henson, D. (2010). Promoting employability skills development in a research-intensive university. Journal of Education and Training, 49 (2), 261-275.

Berry, S. \& Bailey, T. (1992). The double helix of education and the economy. New York: Columbia University, Institute on Education and the Economy.

Bohloko, G. \& Mahlomaholo, S. (2008). Work Integrated Learning Quality Partnerships: The case of the Central University of Technology, Free State. In WACE/ACEN Asia Pacific Conference 2008 E-Proceedings, 56-66.

Collaizi, P.F. (1978). Psychological research as the phenomenologist views it. Oxford: Oxford University Press.

Dacre Pool, L. \& Sewell, P. (2007). The key to employability: Developing a practical model of graduate employability. Journal of Education and Training, 49 (4), 277-289.

Drisko, J.W. (1997). Strengthening qualitative studies and reports: Standards to promote academic integrity. Journal of Social Work Education, 33 (1), 185-197.

Engestrom, Y. (2001). Expansive learning as work. Towards an activity theoretical reconceptualization. Journal of Education and Work, 14 (1), 133-156.

Grubb, W.N. \& Kraskoukas, E. (1993). Building Bridges. Vocational Education Journal, 68 (2), 24-25.

Guile, D \& Griffths, T. (2001). Learning through work experience. Journal of Education and Work, 14, 113-131.

Henderson, J.A. \& Smith, J.J. (2002). Academia, industry, and the Bayh-Dole Act: An implied duty to commercialise. Centre for Integration of Medicine and Innovative Technology. Last available at http://www.cimit.org/news/regulatory/coi part3.pdf.

Jackson, D. (2010). An international profile of industry-relevant competencies and skills gap s in modern graduates. International Journal of Management Education, 8 (3), 29-58

Lankard, B.A. (1993). Integrating Science and Maths in Vocational Education. Adult, Career and Vocational Education, 355-456.

Lincoln, Y.S \& Guba, E.G. (2000). Naturalistic inquiry. London: Sage

Moore, M.G. (1991). Distance Education Theory. The American Journal of Distance Education, 5 (3), 1-6.

Nelson, A.J. (2005). The market economy, and the scientific commons. Research policy, 33 (3), 455-471.

Nonaka, I. (1994). A Dynamic Theory of Organizational Knowledge Creation. Organisational Science, 5(1), 14-37.

Patton, M.Q. (2002). Qualitative evaluation and research methods. Thousand Oaks, CA: Sage Publication.

Reagan, R. \& McEvily, B. (2003). Network Structure and Knowledge Transfer: The Effects of Cohesion and Range. Administrative Science Quarterly, 48(2), 240-267.

Santoro, M.D \& Betts, S.C. (2002). Making Industry-University Partnerships Work. Research Technology Management, 45(3), 42-46.

Smith, E. (2002). The relationship between organisational context and novice workers' learning. International Journal of Training and Development, 6, 254-262.

Smith, P.L. \& Ragan, T.J. (2000). Instructional design. Upper Saddle River, New Jersey: Prentice-Hall.

Smith, R. \& Betts, M. (2000). Learning as Partners: Realising the Potential of work-based Learning. Journal of Vocational education and Training, 52(4), 589-604.

Vahasantanen, K. \& Etelapelto, A. (2009). Vocational teachers in the face of a major educational reform: individual ways of negotiating professional identities. Journal of Education and Work, 22, 15-33. 